\title{
Simulate the Honeycomb System as an Inspirational Design Concept in the Field of Furniture
}

\author{
Dr. PhD .Dalia Mahmoud Ibrahim Khalil
}

Lecturer - Department of Metal Furniture and Constructions Design - Faculty of Applied arts - Helwan University

\begin{tabular}{l|l|l|l|} 
Submit Date:2020-05-29 17:12:36 | Revise Date: 2021-04-07 15:50:22 |Accept Date: 2021-04-10 23:09:38 & |
\end{tabular}

DOI: 10.21608/jdsaa.2021.30540.1058

KEYWORDS:

Nature Simulation - Bionics -

Honeycomb system - Furniture

Design.

\begin{abstract}
:
The concept of nature simulation is associated with engineering technology, so the designer was inspiring from it the composition and formation systems that exist in organisms (live beings) featuring and accuracy and balance to find design solutions. One of those rich genius systems in its balance, strength and beauty is the honeycomb system which was inspirer for many architectural, engineering and product designs. So, areas for inspiration from the honeycomb structure system were varied in the fields of architecture, interior design, industrial designs and furniture, this extended to the innovation of many engineering and technological systems. These systems, which are inspired by the honeycomb ., have innovated many design solutions and engineering innovations that can be employed in the field of furniture design in general and the design of flexible multi-purpose furniture in particular.
\end{abstract}

The Research Problem: The necessity of working to find inspiration ways innovated and developed from the honeycomb system, and how to derive from this balanced and accurate system, and how can we benefit from those ways in the field of furniture design.

The Research Target: The research aims to study the honeycomb system and clarify its effect to get new concept for furniture design. The Research Hypotheses: The researcher believes that honeycomb technology can help furniture designers to reach innovative designs that carry the characteristics of this genius system.

The Research Methodology: The researcher relied on the analytical, inductive and descriptive method.

The Research Themes: The researcher discussed the idea of inspiration in general and the formal, functional and environmental fields of inspiration.

Inspiring from honeycombs and considered it as an inspirer through different fields, especially in the field of architectural design and furniture design.

The effect of being inspired by honeycombs to reach the honeycombs system, and how this system was developed to enter most important industries.

The researcher studied this development in general up to the effect of this system on the manufacture of fixed and flexible furniture. 


\section{INTRODUCTION:}

Inspiration from nature is part of the meditation cult that Allah (The God) has commanded us. Whenever a person thinks about Allah's creation, he finds a lot of perfect beauty and dazzling technology.Inspiration from nature depends not only on imitating the shapes of organisms and simulate their appearances, but the inspiration from nature goes beyond to reach a different point of view and studying the philosophy behind the perfect ecosystem of organisms.Inspiration from nature has multiple forms and functions, and the terminology is multiplied according to the concepts on which each term depends.Design has a set of concepts that link us to environmental design on one hand and technical design on the other hand.

In the following table a set of terms and their concept from the industrial designer's point of view.

Table (1)a set of terms Inspiration from nature

\begin{tabular}{|l|l|}
\hline Bio-inspiration & $\begin{array}{l}\text { It is a field that monitors the wonderful } \\
\text { functions that characterize living things, trying } \\
\text { to strip and imitate those functions but } \\
\text { inference is made through inspiration, not } \\
\text { simulations. }\end{array}$ \\
\hline $\begin{array}{l}\text { Biomimetics } \\
\text { Biomimicry }\end{array}$ & $\begin{array}{l}\text { It is the imitation of the models, systems, } \\
\text { elements and strategies of nature for the } \\
\text { purpose of solving complex human problems. }\end{array}$ \\
\hline Bionics & $\begin{array}{l}\text { Benefiting from nature and its designs in the } \\
\text { technical fields. }\end{array}$ \\
\hline
\end{tabular}

From the table above, we can conclude that design inspiration from nature has three levels, each overlaps with one another and differs in other aspects. Ref $(24,615-593)$

- The first level aims to simulate the shape or apparent structure.

- The second level aims to simulate laws, functions, or deep structure.

- The third level aims to simulate the symbol behind the implicit idea or intellectual framework.

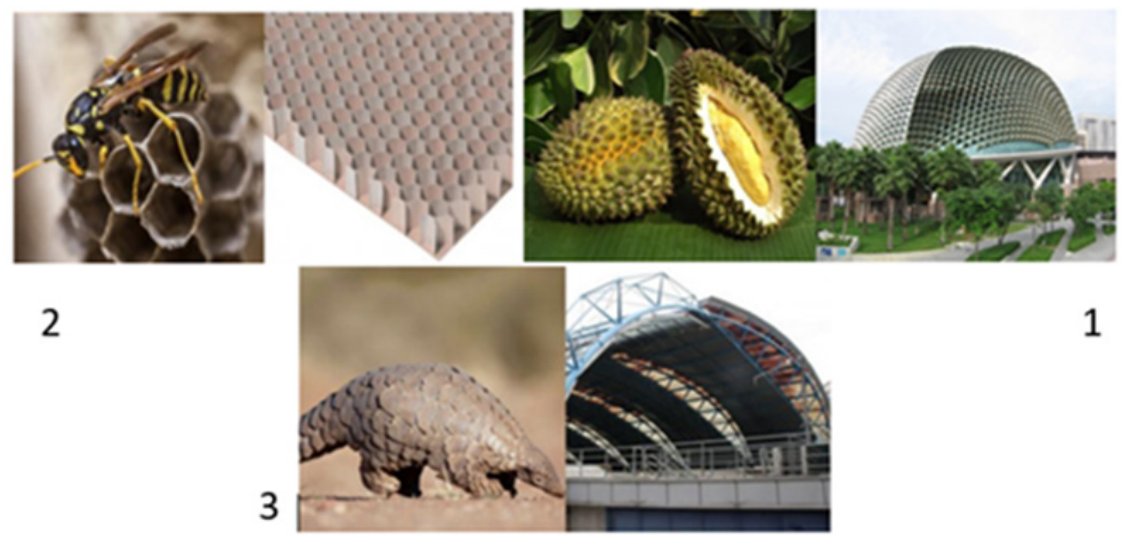

Figure(1)(1(the apparent structure))(2(deep structure))(3(intellectual framework)) 


\section{THE HONEYCOMB SYSTEM:}

The honeycomb structural shape is one of the most inspiring structural formations for the designer in various aspects of design, the honeycombs system is considered one of the most regular, beautiful and economical natural building system. It also has amazing perfection and strength. The genius of the honeycomb system lies in the combination of unity of design, infinite repetition and balance on one hand, and the highest levels of functionality and economy on the other hand. The beautiful regularity in the hexagonal form, which considered one of the strongest design forms in balance. The constructed infinite hexagonal gives beauty of shape, precision in design and saving in material. Ref (researcher)

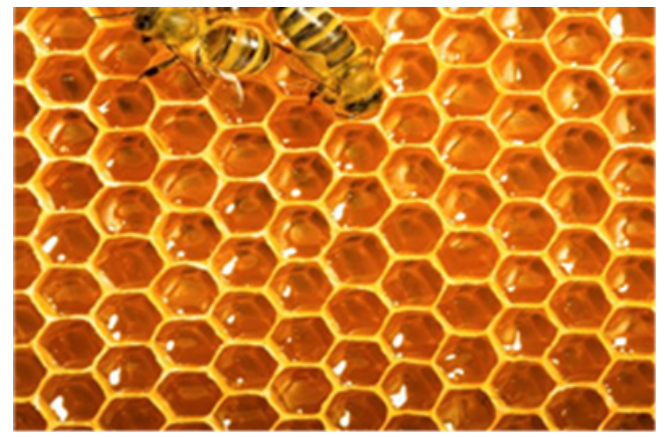

Figure(2)The honeycomb structural shape

\section{SHAPE INSPIRATION FROM HONEYCOMBS SYSTEM:}

Shape inspiration from honeycombs system has two ways; the first relies on honeycombs simulation in accordance with identical, regular, and interconnected to each other hexagons in flat shape simulates the honeycomb's structure directly, the other way simulates the interconnectedness and regularity of the hexagonal honeycomb, but with different shapes and sizes for the hexagon. It helped to spread this method of simulation the parametric design that helped the designer to go out of the design coordinates, but in a balanced and rated way. Ref (researcher)

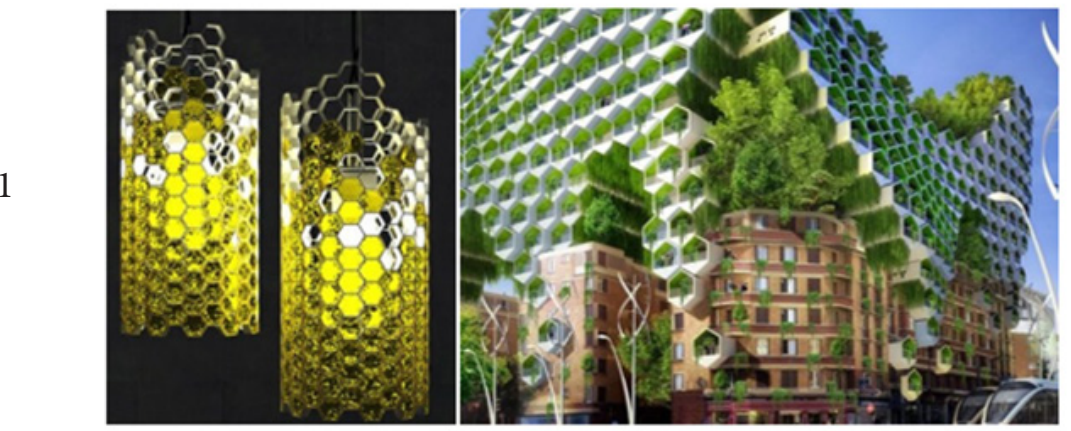

Figure(3)honeycombs simulation in accordance with identical

1-Designed by: YarRassadin Ref(9)

2-Architect: Studio Ardete Ref (13)

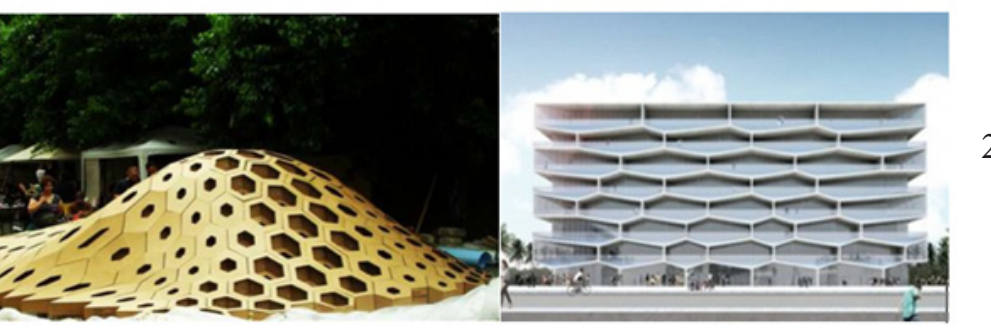

Figure(4)honeycombs simulation in accordance with identical 1-Designed by: Amelia Roblin Ref(20)

2-Architect: HKS architects and michaeldiggiss architects Ref(12) 


\section{INSPIRATION FROM THE HONEYCOMB IN ARCHITECTURE:}

Table (2)Inspiration from the honeycomb in architecture

\section{Building Name: Honeycomb Refugee Skyscraper. Designers:NaelBadr, Noel Maestro, Hagar Elahmar}

Design Idea: It is a design idea to build a skyscraper for the Syrian refugees in the Zaatari Village in Jordan and it is known for the production of honey so the designers had the idea of simulating a beehive based on the principle of sustainability to provide the needed food for the residents of the building and this design was among the selection of the judges for The Global Skyscraper Competition 2017 which is an annual competition established in 2006 and is one of the most important international architectural competitions

\section{Building Name: The Honeycomb \\ Designer: HKS Architects}

Design Idea: A building under construction in The Bahamas has announced the design of the company that owns it (Bjarke Ingels Group (BIG)). The design was inspired by the beehive system without fully adhering to the equality of the hexagons the design emerged with an indirect, diversified simulation.

\section{Building Name: Hexalace Designer: Studio Ardete}

Design Idea: The Hexalace building in Mohali (Punjab), India 2018 was designed with a glass front and due to the high temperatures in Mohali, it was designed with a facade of cement with a thickness of 3 inches inspired by honeycombs Hexalace

\section{Building Name: Honey Comb Music Designer:WolfgangButtress}

Design Idea: UK Pavilion Expo Milan 2015: The British artist devised the design from the bee buzzing in her home and the bee's sound frequencies.

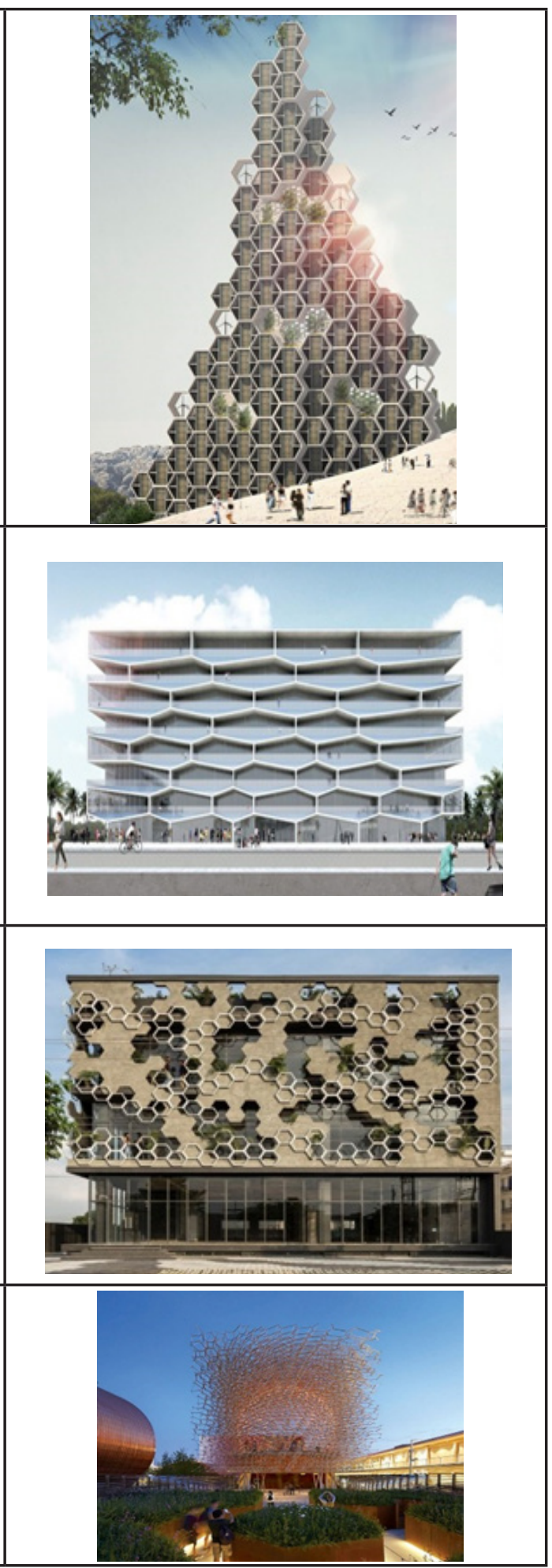

$\operatorname{Ref}(10,11,12,18)$ 


\section{INSPIRATION FROM THE HONEYCOMB IN FURNITURE:}

Table (3)Inspiration from the honeycomb for furniture

\section{Schema Honey Comb Small Table Lamp Designed by: Oggetti}

This piece was designed by a Filipino designerand was made from galvanized iron inspired by beehives in their arrangement and hexagonal system.

\section{Crystal Comb the Beehouse Lamp Designer: YarRassadin}

This piece was designed by a Russian designer made from white and yellow plastic as an expression of honey-filled cells, which is a direct simulation of the idea of beehives.

\section{Collection Honey \\ Designer: Sergio Cordero Álvarez}

This piece was designed by a Spanish design company and it is a small coffee table made from a metal structure in the form of beehives is carried on metal legs and the hexagons are filled with wooden parts that take on the color of natural beehives as a simulation of the idea.

\section{Module Hlive Designer: Dar en art}

This piece was designed by the European company, Dar en art and was implemented from wood with an idea inspired by the beehive in each unit separately and in the general composition of the units to create a selected furniture unit consisting of a hexagonal composition of the beehive to form a unit of office shelves.
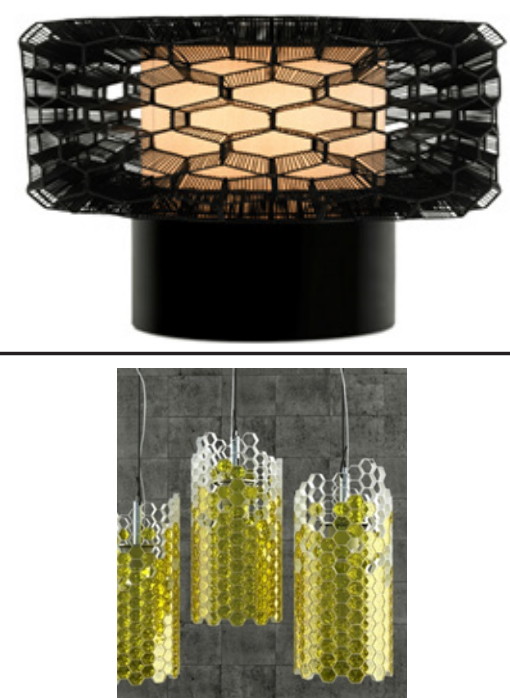

$\operatorname{Ref}(1,2,3,9)$ 
FUNCTIONAL INSPIRATION FROM THE HONEYCOMB SYSTEM:

The functional inspiration of honeycombs took many forms in design aspects, where scientists had to study the technical and technique elements of the honeycomb system, so those studies emerged, so it yielded more than 500 types of raw materials based on honeycomb technology used in various industries.

The honeycomb technology was discovered in China from 200 years in the manufacture of cardboard, then it was first used from wood in 1845 to withstand pressure to protect eggs. With the development of the material using different types of wood, the sandwich panel was invented to be used for the first time in 1919 in the manufacture of aircraft.During WWII, honeycomb technology was used in sandwich panel made of plywood covered with plank wood in German warplanes. The first use of metal ore in honeycomb technology was in 1945 using aluminum ore, and this was a major shift in many industries, the most important of which is the manufacture of aircraft, ships and cars. Ref (21p43)

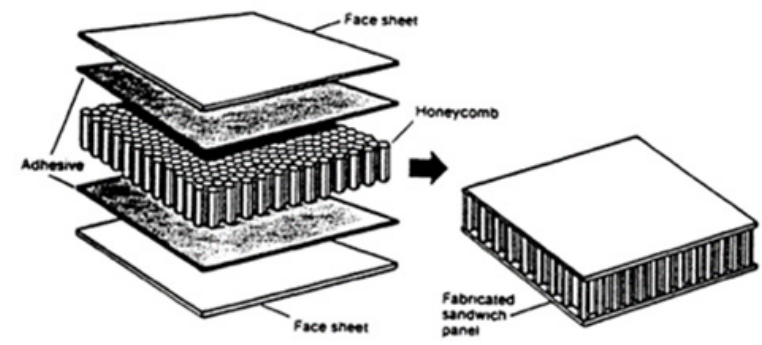

Figure(5) honeycomb sandwich panel

\section{THE USE OF HONEYCOMB TECHNOLO- GY IN INDUSTRIES:}

For many years, many companies and research centers have been persevering to develop the use of honeycomb technology and develop raw materials for their production to reach the maximum benefit in terms of economy, productivity, light weight, durability and environmental depending on the nature of the industries it is used in them. The honeycomb sandwich consists of two exter- nal layers, sometimes its raw material differ and meet in most cases, and a filling of conjoined identical hexagons that give the main size of the sandwich.The thickness of each layer varies depending on the function it is made for,the thickness of the layers and its raw material are determined according to the durability, and the flexibility and weight ratio required for the function, as shown in the following figure; as $(\mathrm{H})$ is the sandwich thickness and $(\mathrm{T})$ is the thickness of both the upper and lower layers of the sandwich. $\operatorname{Ref}(21 \mathrm{p} 104)$
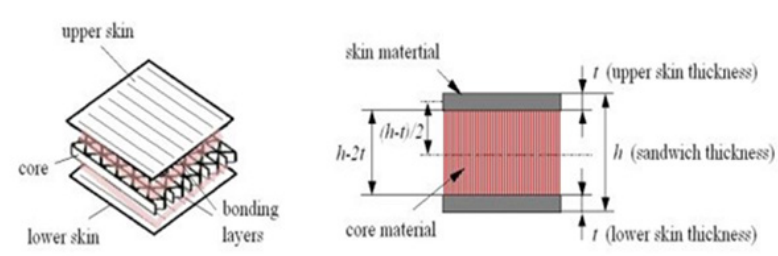

Figure(6) honeycomb sandwich panellayers

The use of honeycomb technology in the manufacture of aircraft, ships and cars has spread since the middle of the last century.Due to the superiority of this technology on the part of light weight relative to durability. To achieve the maximum benefit, the manufacturing materials for the honeycomb sandwich differed according to the required use, sometimes the filling material is fixed into the sandwich and change the skin change both, figure (7) . Ref (6)
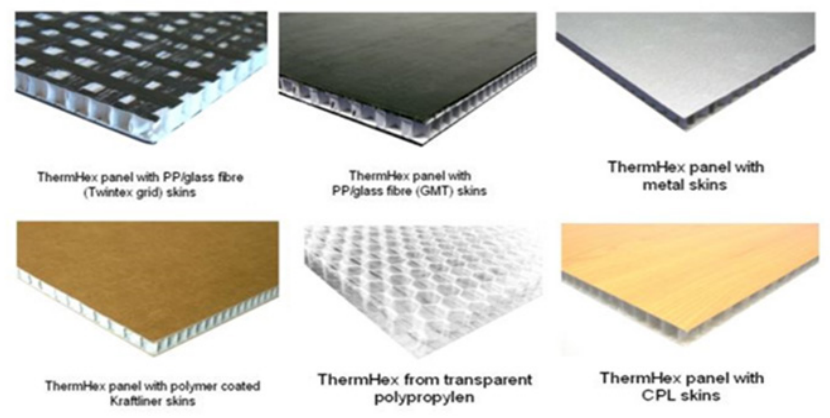

Figure(7)different materials for honeycomb sandwich panel 
HONEYCOMB SANDWICH CHARACTERISTICS:

Honeycomb's characteristics were distinguished by a set of features that not only made it a tool for developing different industries but also a catalyst for inventing completely new products.Among the distinctive characteristics of the honeycomb: Ref (6)

- High strength ratio relative to the weight as the core of its advantages.

- High air efficiency.

- High ratio of exposed surface area relative to total volume.

- Constant crushing force under pressure.

- Unified distribution of stress in the sandwich structure.
- Outstanding hardness.

- Thermal and acoustic insulation.

- Flexibility and fire resistance.

- Moisture and corrosion resistance.

The idea of honeycomb technology and its characteristics depended on the hexagonal interlocking formations in the sandwich filling that creates spaces inside, which gives it the characteristics of vacuum insulators. The genius of these tangles gave the sandwich a strong bearing strength in the vertical direction of up to 400 times of the weight of the sandwich in some composite structure ores like EPP and PU.The following figure shows the durability of the sandwich according to the thickness of the sandwich and the skin. Ref (19)

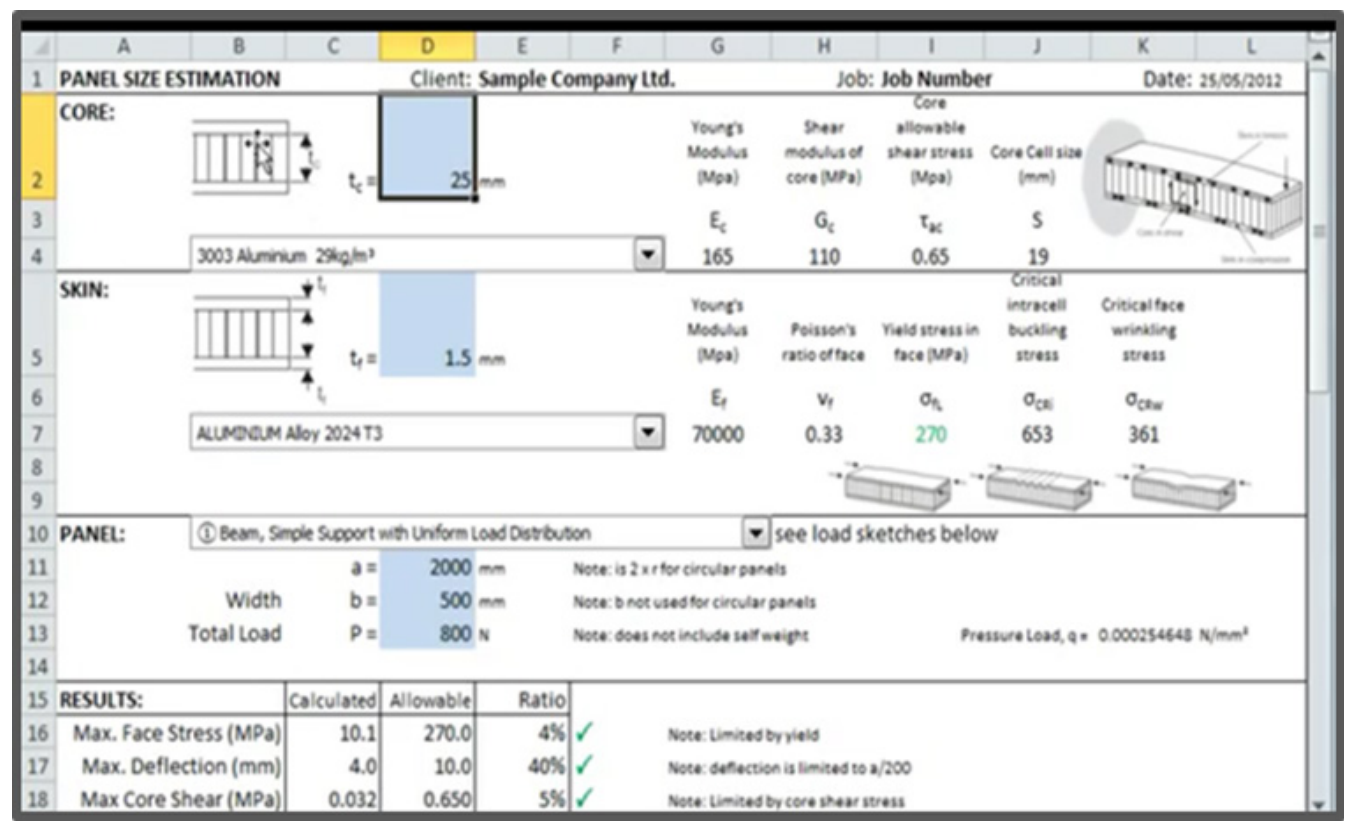

Figure(8)the durability of the sandwich according to the thickness of the sandwich and the skin.

The idea of strength in the contiguous hexagons lies in the six supports of each hexagon unit from its ends, and combines them with other and other. Vertical loads are distributed over the surface area of the sandwich, while the pressure in the horizontal direction differs based on two things; the first is the material from which the content of the internal sandwich itself is made, in most cases, the materials used are flexible and light and the horizontal pressure makes the sandwich bend over, this is useful when used in flexible products that need compressive strength in the vertical direction and flexibility in the horizontal direction. The second thing that controls the strength of the horizontal pressure is the type of skin material; the stronger the raw material is and its thickness is appropriate for this, it bears more force in its cross section than this direction. Figure (9) shows the difference in the sandwich unit between horizontal and vertical pressure. Ref (researcher( 


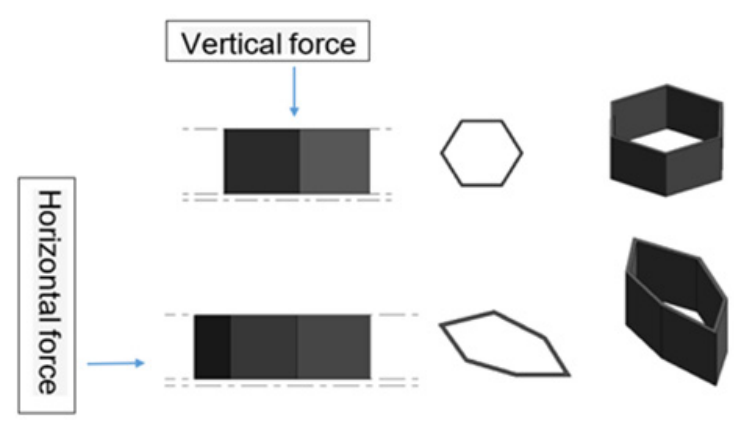

Figure(9) the difference in the sandwich unit between horizontal and vertical pressure.

\section{ADVANCED HONEYCOMB TECHNOLOGY}

The advancement in honeycomb technology has taken several main pivots to serve the needs of industry and people in general in the future, some researchers have replaced honeycomb materials with environment friendly ones, although reaching many materials plays this role, but it is not in the engineering and mechanical specifications of similar, in addition to that it is somewhat expensive and research is underway to reach the same level of mechanical chrachteristics with composites with biotic basis. On the other hand, the development process was seeking access to a honeycomb that is resistant to severe effects. Researchers from Cockrill Engineering College at the University of Texas at Austin invented a new honeycomb structure that can handle the intense pressure strength and sudden effects, it is divided into levels of shock and this technology has many applications, including helmets, military aviation, bicycles and cars. Ref(8)

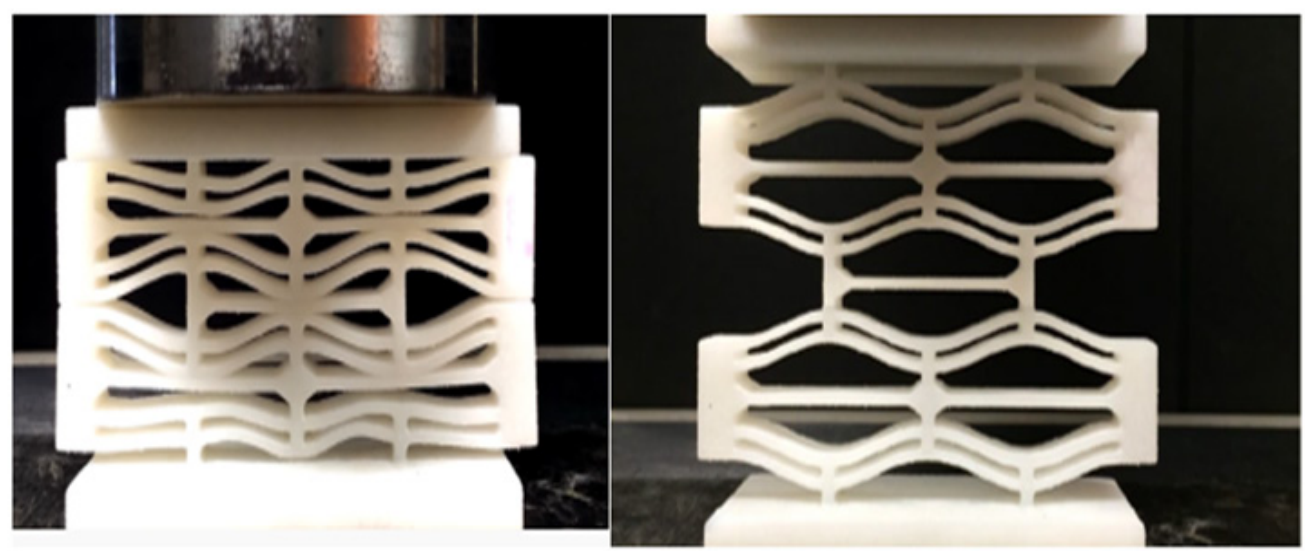

Figure(10)Advanced Honeycomb Technology

\section{THE VARIETY IN USES OF HONEYCOMB SANDWICH}

Honeycomb, by its superior strength to weight ratio, has proven to be a very versatile material in manufacturing in general,especially in complex assemblies that require simple and complex curves. New materials such as advanced composites and advanced treatment techniques have expanded the applications of the honeycomb sandwich,it has recently been widely used in the manufacture of airframes, ships, spacecraft, transportation equipment, building materials, car bodies, and recreational and sporting goods. Honeycomb technology has also entered into the furniture industry, which had a major effect on it, either on fixed or flexible furniture. Ref (6)

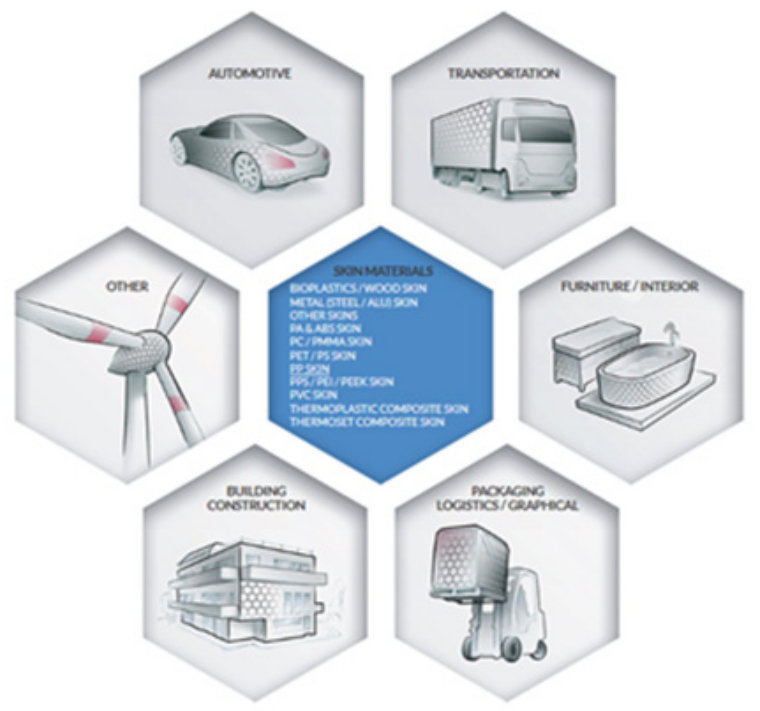

Figure(11) Some uses ofhoneycomb sandwich 


\section{THE USE OF HONEYCOMB TECHNOLO- GY IN FURNITURE}

The idea of using honeycomb technology in the furniture field depends on the main feature of it, which is light weight versus durability,but, soon the honeycomb technology demonstrated impressive new features that are directly related to furniture design more than others.

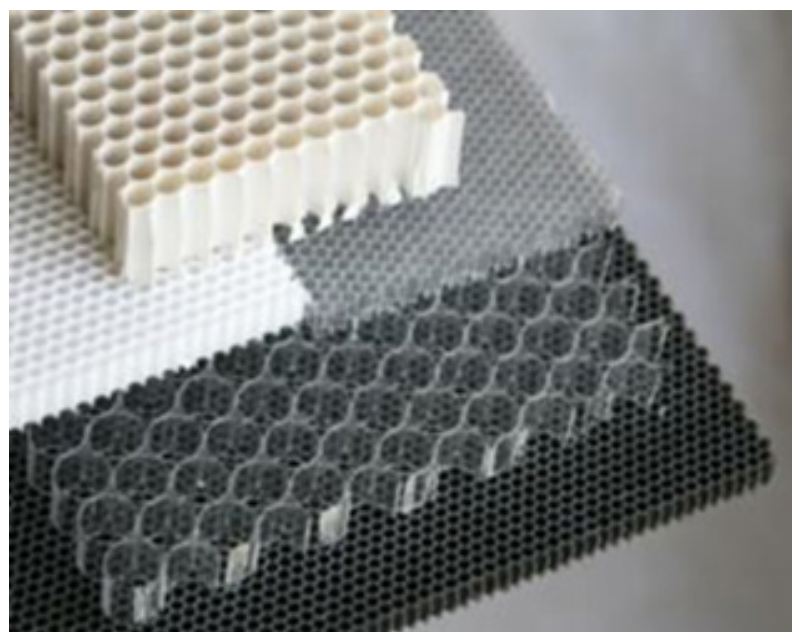

Figure(12) different materials include honeycomb for furniture manufacturing

THE KEY DISTINCTIVE CHARACTERISTICS OF HONEYCOMB TECHNOLOGY IN FURNITURE

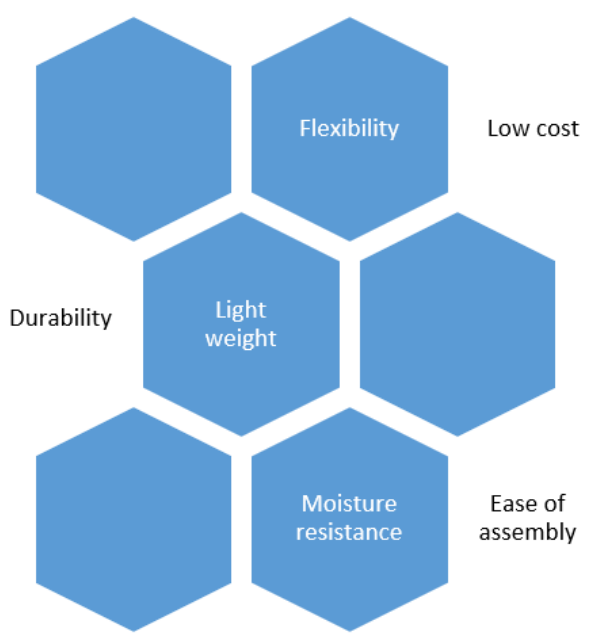

Figure(13)The key distinctive characteristics of honeycomb technology in furniture

Honeycomb technology has the advantage of preserving its distinctive characteristics while changing the materials it is made from, but it acquires other additional characteristics depending on each material and its characteristics,this gives that technology endless qualities, so the designer finds what he wants wherever he wants.In the following table, some applications of honeycombs with different raw materials, the characteristics of each of them and the possibility of their use in the field of furniture industry. Ref (researcher(

Table(4)some applications of honeycombs in furniture

\begin{tabular}{|l|l|l|l|}
\hline \multicolumn{1}{|c|}{ Material } & \multicolumn{1}{|c|}{ Properties } & Exploit in furniture \\
\hline Sponge printed & Durability/ Light weight & $\begin{array}{l}\text { In car seats, office } \\
\text { chairs, and chairs that } \\
\text { are used for a long time. }\end{array}$ \\
\hline Metal & $\begin{array}{l}\text { Durability / Hardness } \\
\text { Inelastic, the aluminum } \\
\text { material is lightweight } \\
\text { iron more flexible than }\end{array}$ & $\begin{array}{l}\text { In car seats, wheel- } \\
\text { chairs, hospital furni- } \\
\text { ture and office furniture. }\end{array}$ \\
\hline
\end{tabular}




\begin{tabular}{|c|c|c|c|}
\hline polycarbonate panels & $\begin{array}{l}\text { fire protection / co-ex- } \\
\text { truded UV protection/ } \\
\text { transparency rate can } \\
\text { exceed } 95 \% \text { / Various } \\
\text { colors }\end{array}$ & 1 & $\begin{array}{l}\text { Partitions, office furni- } \\
\text { ture and store furniture. }\end{array}$ \\
\hline Gel & $\begin{array}{l}\text { Flexible, can not handle } \\
\text { vertical nor horizontal } \\
\text { pressure, but regains } \\
\text { its original shape as } \\
\text { soon as the pressure is } \\
\text { removed. }\end{array}$ & & $\begin{array}{l}\text { In car seats, office } \\
\text { chairs, and chairs that } \\
\text { are used for a long } \\
\text { time. }\end{array}$ \\
\hline Acrylic PMMA & $\begin{array}{l}\text { the transparency rate } \\
\text { can exceed } 95 \% \text {. } \\
\text { Various colors, long } \\
\text { lasting. } \\
\text { Very bright, easy to } \\
\text { clean } \\
\text { Easy mold Non-toxic } \\
\text { acrylic sheet }\end{array}$ & & $\begin{array}{l}\text { Tables, partitions, office } \\
\text { furniture, shelving units } \\
\text { and store furniture. }\end{array}$ \\
\hline $\begin{array}{l}\text { Honey comp: carton } \\
\text { Skin: wood }\end{array}$ & $\begin{array}{l}\text { Light weight/ } \\
\text { Durability/ Ease of } \\
\text { installation }\end{array}$ & 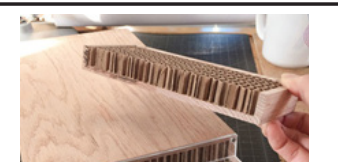 & $\begin{array}{l}\text { Tables, shelving units, } \\
\text { cabinets and display } \\
\text { units }\end{array}$ \\
\hline $\begin{array}{l}\text { Honeycomb: polypro- } \\
\text { pylene (PP) } \\
\text { Skin :mdf } \\
\text { ABS edge protection }\end{array}$ & $\begin{array}{l}\text { Light weight/ } \\
\text { Durability/ } \\
\text { Moisture resistance }\end{array}$ & & $\begin{array}{l}\text { Tables, shelving units, } \\
\text { cabinets, kitchens and } \\
\text { display units }\end{array}$ \\
\hline
\end{tabular}

$\operatorname{Ref}(4,5,13,14,15$,

THE USE OF HONEYCOMB TECHNOLOGY IN FLEXIBLE FURNITURE

Due to the nature of flexible honeycomb technology, this flexibility had to be used in applications for designing flexible furniture that is easy to fold, transport, disassemble and install. So, some designers inspired from the honeycomb technology some ideas that aimed to fold the furniture unit in the horizontal direction, but the materials used were either from pasteboard or from the treated cardboard, which its durability was weak relatively, figure (14). Ref (7) 


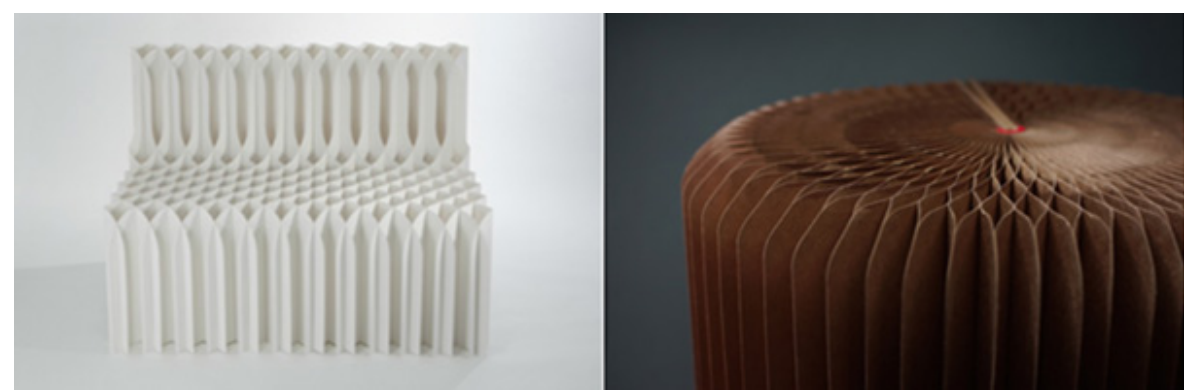

Figure(14) flexible furniture made from pasteboard or from the treated cardboard

By the development of raw materials that form the honeycomb slice, such as plastics and treated petroleum raw materials (such as acrylic, propylene, plaster, rubber, ...), the designer had to benefit from of the development of this technology and produce a sandwich with flexibility, durability and virtual longevity, so a team of American design- ers included (Daniela "Dani”'Terminel- Mohamed "Mido" Kamal- Reham"Remo" Khalif( Innovated a sofa based on honeycomb technology made from polyester fiber, figure (15). This design carries many inspiring ideas for furniture designers to innovate furniture based on honeycomb, that is flexible, lightweight and economical. Ref (16)
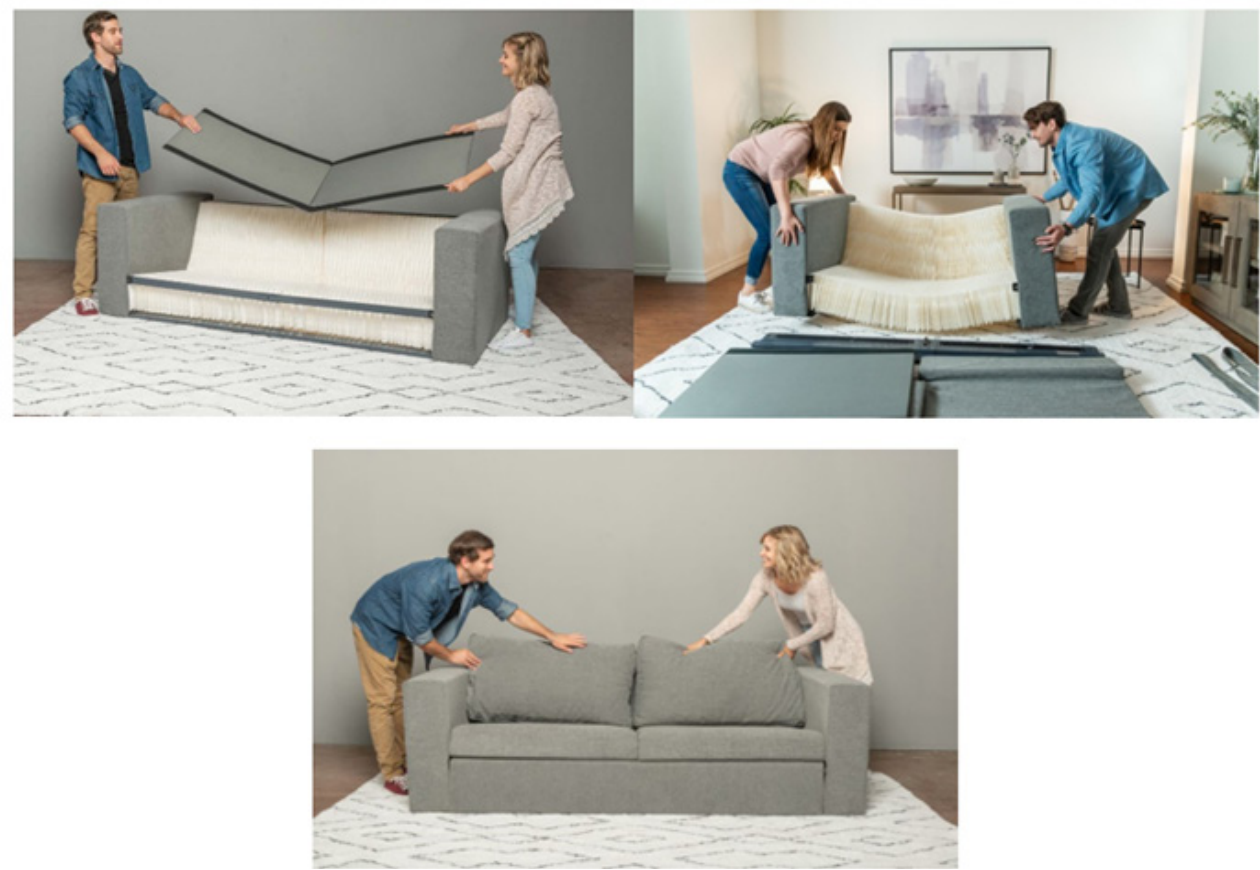

Figure(15)A sofa based on honeycomb technology (Elephant in the box)

\section{CONCLUSIONS:}

- Inspiration from nature: Nature is always a fertile source for the designer at all levels of inspiration (formal - functional - symbolic).

- Honeycombs are creative natural sources of inspiration that provide the designer with countless ideas, whether formal or functional.

- The diversity in the raw materials used in the honeycomb sandwiches gave this technology impressive additional characteristics.
- Honeycomb technology is a new concept for furniture design, especially the flexible one.

\section{RECOMMENDATIONS:}

- The necessity for the designer to pay attention to all aspects of inspiration from nature (formal functional - symbolic).

- The necessity of studying modern raw materials with their effect on discovering new applications 
in the field of furniture.

- Establishing experimental laboratories that enable the designer to study and experiment with design ideas in other industries.

\section{REFERENCES:}

1. Oggetti.(2019) Schema Honey Comb Large Table Lamp[Online] Available at https://www.dlaguna. com/oggetti-italian-lighting-schema-honey-combsmall-table-lamp.html ( Accessed: 25/8/2019)

2. Pramono,D.(2017) moduler JavaScript in different syntaxes [Online] Available at https://blog.cloudboost.io/@djoepramono (Accessed:29/9/2019)

3. Altinox.(2014) Honey/steeland coffee table https:// www.archiproducts.com/en/products/altinox/lowsteel-and-wood-coffee-table-honey-steel-andwood-coffee-table_205050 (Accessed:25/8/2019)

4. Saunrers,S.(2019) 3D Printing Materials [Online] Available at https://3dprint.com/237610/sinterit-flexible-strong-textiles-for-opera-costumes/ Accessed:9/1/2020)

5. Jody,chi.(2016) Common Collection: Leveraging Under-Valued Materials [Online] Available at https://productsofdesign.sva.edu/blog/thesis-permanism Accessed:9/1/2020)

6. Econcore.(2019) Core material and process [Online] Available at http://www.econcore.com/en/ technology/thermhex Accessed:29/9/2019)

7. Morgan,H.(2013) Flat-Pack Paper chair [Online] Available at https://inhabitat.com/flatpack-paper-chair-is-lightweight-modular-concept-fromsekita-design-studio/sekita-folding-paper-origami-chair/ (Accessed: 3/1/2020)

8. Wade,A.(2015)Honeycomb structure offers energy-absorbing applications [Online] Available at https://www.theengineer.co.uk/honeycomb-structure-offers-energy-absorbing-applications/ ( Accessed:13/12/2019)

9. Berrones, A(2008) Crystal Comp [Online] Available at https://www.yankodesign.com/2008/09/25/ crystal-comb/comment-page-1/ ( Accessed: 25/1/2020)

10. Gonzalaz,MF.(2018)Hexalace/Studio Ardete [Online] Available at https://www.archdaily.com/899510/hexalace-studio-ardete ( Accessed:25/1/2020)

11. Buttress,W.(2015) UK Pavilion- Milan Expo2015/ [Online] Available at https://www.archdaily. com/627728/uk-pavilion-milan-expo-2015-wolfgang-buttress (Accessed:29/9/2019)
12. Grünert,S.(2014) Bjarke ingles group envisions honeycomb resort in Bahamas [Online] Available at https://www.designboom.com/architecture/bjarke-ingels-group-envisions-honeycomb-resort-in-bahamas-01-27-2014/ ( Accessed:20/1/2020)

13. Wang,D.(2017)Hanycomp panels[Online] Available at https://www.pinterest. com/pin/443112050839400305/ ～～Accessed:24/12/2019)

14. (2016)Polycarbonete panels [Online] Available at https://kapoorplastics.wordpress.com/2016/04/02/ polycarbonate-panels-the-best-alternative-to-glasses/ (Accessed: 19/12/2019)

15. Morgan,H.(2015) Core material and process [Online] Available at https://www.groupon.com. $\mathrm{au} /$ deals/mnb-variety-imports-716320445 ( Accessed: 20/12/2019)

16. Terminel ,D/ Kamal ,M/ Khalifa, R(2019)Elephant in the box[Online] Available at https://elephantinabox.com/ ( Accessed: 22/12/2019)

17. (2013)Honeycomb structure [Online] Available at https://en.wikipedia.org/wiki/Honeycomb_structure (Accessed:20/12/2019)

18. Badr,N/Maestro,N/Elahmar,H(2017)Honeycomb Refugee Skyscraper[Online] Available at http:// www.evolo.us/honeycomb-refugee-skyscraper/ (Accessed:25/12/2019)

19. Doyle,J.(2012)Honeycomb panel design tool [Online] Available at https://www.youtube. $\mathrm{com} /$ watch?v=Y2RR2P2goFY\&t=132s ( Accessed:20/1/2020)

20. Roblin,A.(2011) Bulous Honeycomb sculptures [Online] Available at https://www.trendhunter. com/trends/hexigloo ( Accessed:5/1/2020)

21. T.N. Bitzer,(1997) Honeycomb Technology: Materials, Design, Manufacturing, Applications and Testing Springer-Science+Business Med ia, B. V.. [Online] https://www.springer.com/gp/ book/9780412540509 ( Accessed:4/8/2020)

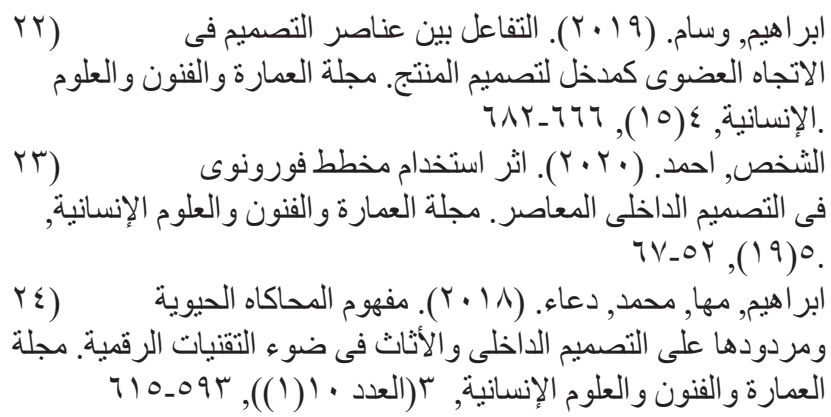

